\title{
Paleo sea-level changes in the Black Caspian Seas: Links to river runoff and global climate change
}

\author{
Alexander Kislov and Pavel Toropov \\ Dept. of Meteorology and Climatology, Faculty of Geography, Moscow State University, Russia; avkislov@mail.ru, tormet@inbox.ru
}

\section{Introduction}

To assess the link between climate variability and hydrological regime, we focused our study on the mid-Holocene (6 ka years BP) and the last cold period of the Late Quaternary (21 ka BP). We discuss how well current general circulation models (GCMs) can reproduce river runoff changes and, consequently, variations in closed lake level under contrasting climate conditions. The Paleoclimate Modeling Intercomparison Project (PMIP) (Joussaume and Taylor, 1995) has run simulations that are used in this study. The rivers of the East European Plane (EEP) were selected for analysis. Feed of rivers is determined by the balance of precipitation and evaporation in the catchment, hence river runoff change responds immediately to climate changes. It is important that both precipitation and evaporation are calculated by a GCM. Moreover, on large planes, such as the EEP, GCM data much better reflect the state of climate compared to areas with complex mosaic surface conditions. Additionally, large amounts of paleoclimate data exist on the EEP for selected periods of the past.

\section{Modern GCM runs}

Prior to investigating river runoff changes in the past, it is necessary to be convinced that GCMs are capable of simulating the modern climate state. It was shown that only large river catchments (covered by about 15 GCM cells with typical GCM horizontal resolution $2.5 \times 2.5^{\circ}$ ) can be correctly analyzed and analyzing the smaller river basins is not meaningful. The runoff value is estimated in the framework of a GCM as the annual value P-E (precipitation minus evaporation). If the error of modeled runoff is $\pm 20 \%$, the result was considered to be "successful" because in this case deviation does not exceed observed natural variability. The data of these "successful" models were examined more closely by running

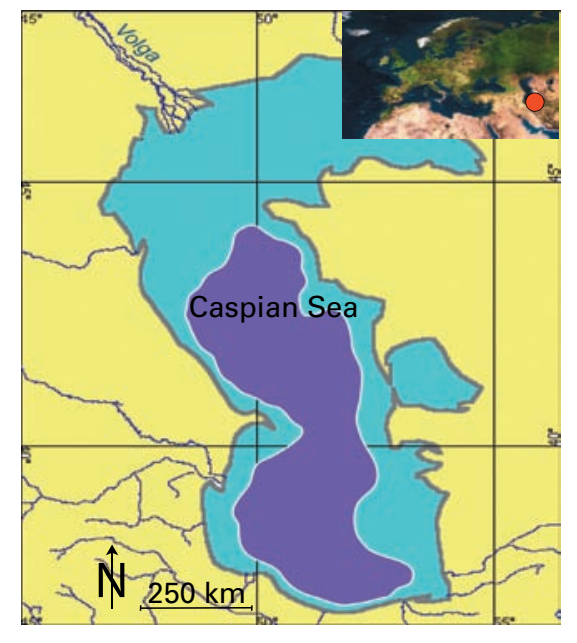

Fig. 1: Area of the Caspian Sea during the midHolocene/modern (blue color) and regression stage of the LGM evaluated based on the PMIP1 data (purple color).

simulations of other climate regimes. Validation can be done on the basis of comparison of modeled P-E with data of standard hydrological observation in river estuaries. The majority of models simulate runoff to the Baltic Sea well (Table 1), but only a few models are capable of reproducing runoff to the Black Sea and the Caspian Sea with good accuracy.

\section{The mid-Holocene}

The mid-Holocene study within PMIP 1 focussed on the 6 ka BP climate. As a first approximation, SSTs were prescribed to be the same as today, the $\mathrm{CO}_{2}$ concentration was similar to its pre-industrial value of $280 \mathrm{ppm}$, and vegetation and land-surface characteristics were held constant. Climate change is only influenced by the change of insolation forcing.

Calculations indicate that at $6 \mathrm{ka}$ $\mathrm{BP}$ there is no significant change of the EEP river runoff (see Table 2). The Volga River contribution to the total volume of water running to the Caspian Sea slightly increases (93\%) compared to today's climate $(88 \%$ according to PMIP 1 model simulations and $84 \%$ based on observation). In spite of the slight reaction of river runoff to external orbital forcing, it is unexpected that the Caspian Sea level was not stable during the Holocene. The amplitude of sea-level perturbations was several meters (Varushenko et al, 1987).

\section{The LGM}

The time slice at $21 \mathrm{ka} \mathrm{BP}$, as an example of the last glacial maximum (LGM), involves large changes in the surface boundary conditions: ice sheet extent and height, changes in SSTs, albedo, sea level and concentration of greenhouse gases and aerosols, but only minor changes in solar radiation at the top of the atmosphere. Here we look at the results of calculation of annual river runoff volumes for the Caspian and Black Seas. The regions of the modern Baltic Sea and Arctic seas were strongly perturbed during the LGM, and are therefore not included in this study.

At $21 \mathrm{ka} \mathrm{BP}$, the total river runoff to the Caspian Sea (calculated by "successful" models) was substantially decreased ( $50 \%)$ compared to today's climate (see Table 3). The relative contribution of Volga River runoff is $72 \%$. These facts are in accordance with the observational data (Varushenko et al, 1987).

\section{Implications for sea level}

Information about river runoff change also provides a useful guide for conclusions about the status of the Caspian Black Seas. According to the definition of the water budget for closed lakes, the steady-state equation of the annual water budget is:

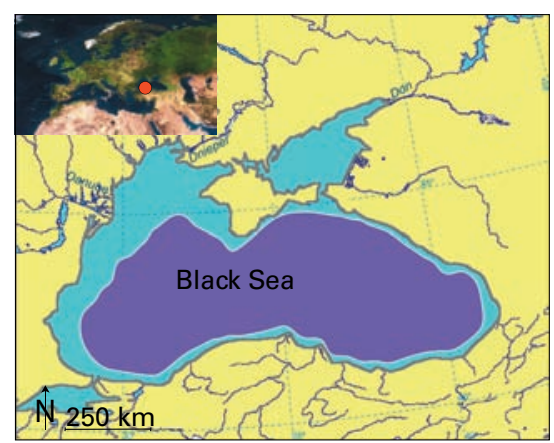

Fig. 2: Area of the Black Sea during the midHolocene/modern (blue color) and regression stage of the LGM evaluated based on the PMIP1 data (purple color). 
Table 1: Today's annual volume of the EEP river runoff $\left(\mathrm{km}^{3}\right)$ into different ocean basins, simulated by the PMIP1 GCMs.

\begin{tabular}{|c|c|c|c|c|c|c|c|c|}
\hline \multirow{3}{*}{ GCM } & \multicolumn{8}{|c|}{ B A S I N S } \\
\hline & \multicolumn{2}{|c|}{ Black Sea } & \multicolumn{2}{|c|}{ Caspian Sea } & \multicolumn{2}{|c|}{ European Arctic seas } & \multicolumn{2}{|c|}{ B altic Sea } \\
\hline & runoff, $\mathrm{km}^{3}$ & error' & runoff, $\mathrm{km}^{3}$ & error & runoff, $\mathrm{km}^{3}$ & error & runoff, $\mathrm{km}^{3}$ & error \\
\hline BM RC & 6,0 & -98 & 68,0 & -75 & 174,2 & -62 & 377,0 & -20 \\
\hline CCC2 & 182,7 & -41 & 242,6 & -11 & 440,6 & -3 & 518,9 & 10 \\
\hline сCM3 & 358,2 & 9 & 308,7 & 13 & 422,5 & -7 & 535,6 & 14 \\
\hline CCSR & 341,7 & 15 & 195,5 & -29 & 307,2 & -32 & 491,1 & 4 \\
\hline CNRM1 & 262,1 & -16 & 191,8 & -30 & 407,4 & -10 & 568,6 & 21 \\
\hline CSIRO & 251,2 & -20 & 209,5 & -24 & 272,8 & -40 & 372,7 & -21 \\
\hline ECHAM3 & 161,1 & -48 & 173,6 & -37 & 462,7 & 2 & 488,7 & 4 \\
\hline GEN2 & 225,2 & -27 & 94,5 & -66 & 222,4 & -51 & 402,9 & -14 \\
\hline GFDL & 238,8 & -23 & 44,3 & -84 & 250,6 & -45 & 416,4 & -12 \\
\hline GISS & 41,3 & -87 & 94,5 & -66 & 277,2 & -39 & 308,1 & -35 \\
\hline LMD5 & 653,3 & 109 & 187,9 & -31 & 201,6 & -55 & 330,2 & -30 \\
\hline MRI2 & 233,1 & -25 & 132,8 & -52 & 308 & -32 & 425,4 & -10 \\
\hline UGAMP & 335,1 & 7 & 229,3 & -16 & 407,5 & -10 & 450,1 & -4 \\
\hline UKMO & 303,8 & -3 & 138,1 & -50 & 339,6 & -25 & 496,3 & 5 \\
\hline UIUC & 515,9 & 65 & 141,6 & -48 & 251,8 & -44 & 434,0 & -8 \\
\hline YONU & 566,5 & 82 & 211,8 & -23 & 262,3 & -42 & 414,8 & -12 \\
\hline ENS $^{2}$ & 292,3 & -6 & 166,5 & -39 & 313 & -31 & 439,4 & -7 \\
\hline SUCS $^{3}$ & 308,7 & -1 & 260,2 & -5 & 428,1 & -5 & 454,3 & -3 \\
\hline $0 \mathrm{bs}^{4}$ & 312 & - & 274 & - & 453 & - & 470,6 & - \\
\hline
\end{tabular}

${ }^{1}$ Relative error (\%); ${ }^{2}$ ENS: Ensemble mean of GCMs data; ${ }^{3}$ SUCS: Ensemble mean of successful GCM data (selected in Table 1); ${ }^{4}$ Obs: Mean of observational data

$$
\text { ef }=Y F
$$

where $F, f, e$, and $Y$ stand for the catchment area, lake area, difference (E-P) over the lake area, and the river runoff from the catchment into the lake, respectively. Variation of the lake area relative to the present status (denoted by index ' 0 ') may be expressed by:

$$
\frac{\Delta f}{f_{0}}=\frac{\Delta Y}{Y_{0}}+\frac{\Delta F}{F_{0}}-\frac{\Delta e}{e_{0}}
$$

It allows us to evaluate the contribution of different factors to change of the level (h) as:

$$
\Delta h=(\Delta h)_{Y}+(\Delta h)_{F}+(\Delta h)_{e}(3)
$$

It is supposed (based on geomorphological evidences) that the configuration of the catchment area of the rivers was principally unchanged at

$21 \mathrm{ka} B \mathrm{P}$, therefore the second term in the Eq. (3) is equal to zero. Value over the Caspian Sea was estimated (based on regional climate modeling (Kislov and Surkova, 1997)) to be small relative to the first term in Eq. (2). Calculations indicate that a decrease of the river runoff causes a substantial drop in the Caspian Sea level $(\sim 50 \mathrm{~m})$ (see Fig. 1). The calculated river runoff for the Black Sea is also substantially decreased ( 50\%) (see Table 3). This fact, coupled with the assumption that due to decreasing sea level the Black Sea was a closed lake at $21 \mathrm{ka} \mathrm{BP}$, allows us to estimate that the drop in level was approx. $200 \mathrm{~m}$ (Fig. 2).

\section{Conclusions}

GCMs are able to correctly repro-

\begin{tabular}{|c|c|c|c|c|c|c|c|c|}
\hline \multirow{2}{*}{ bCMs } & \multicolumn{2}{|c|}{ Black Sea } & \multicolumn{2}{|c|}{ Caspian Sea } & \multicolumn{2}{|c|}{ European Arctic seas } & \multicolumn{2}{|c|}{ Baltic Sea } \\
\hline & runoff, $\mathrm{km}^{3}$ & deviation ${ }^{1}$ & runoff, $\mathrm{km}^{3}$ & deviation & runoff, $\mathrm{km}^{3}$ & deviation & runoff, $\mathrm{km}^{3}$ & deviation \\
\hline BMRC & 337 & $>1000$ & 385,2 & 466 & 564,5 & 224 & 695,1 & $>1000$ \\
\hline CCC2 & 181,7 & -1 & 260,9 & 8 & 425,7 & -3 & 494,1 & -5 \\
\hline CCM3 & 375,2 & 5 & 356,1 & 15 & 419,1 & -1 & 517,5 & -3 \\
\hline CCSR & 304,2 & -11 & 166 & -15 & 311,7 & 1 & 442,2 & -10 \\
\hline CNRM1 & 185,8 & -29 & 153,9 & -20 & 404,9 & -1 & 580,4 & 2 \\
\hline CSIRO & 30,5 & -88 & 60,8 & -71 & 217,5 & -20 & 303,3 & -19 \\
\hline ECHAM 3 & 101,3 & -37 & 138,3 & -20 & 445,8 & -4 & 501,0 & 3 \\
\hline GEN2 & 250,2 & 11 & 88,4 & -6 & 193,9 & -13 & 365,6 & -9 \\
\hline GFDL & 236,2 & -1 & 46,6 & 5 & 249,8 & 0 & 446,7 & 7 \\
\hline GISS & 14,5 & -65 & 115,5 & 22 & 315,3 & 14 & 279,9 & -9 \\
\hline LMD5 & 1088,4 & 67 & 414,8 & 121 & 315,3 & 56 & 652,4 & 98 \\
\hline MRI2 & 239,2 & 3 & 112,7 & -15 & 238,5 & -23 & 408,7 & -4 \\
\hline UG AMP & 327,5 & -2 & 221,8 & -3 & 322,8 & -21 & 371,5 & -17 \\
\hline UKMO & 335,7 & 11 & 146,5 & 6 & 293,7 & -14 & 405,8 & -18 \\
\hline UIUC & 521,2 & 1 & 156,4 & 10 & 232,8 & -8 & 390,1 & -10 \\
\hline YONU & 575,7 & 2 & 209,1 & -1 & 258 & -2 & 412,4 & -1 \\
\hline ENS & 319 & 9 & 189,6 & 14 & 326 & 4 & 454,2 & 3 \\
\hline sucs & 305,7 & -5 & 262 & 5 & 403,7 & -6 & 432,3 & -7 \\
\hline
\end{tabular}
duce elements of the hydrological

Table 2: Annual volume at $6 \mathrm{ka} \mathrm{BP}$ of the EEP river runoff $\left(\mathrm{km}^{3}\right)$ into the different basins cycle (precipitation, evaporation and runoff) for large rivers under different climatic situations. The differences in hydrological mode of the rivers of the EEP between 6000 years BP and today are small. This fact corresponds to results of paleohydrological reconstructions and is particularly interesting from the point of view that the warm mid-Holocene is often considered to be an analog of expected future climate warming conditions.

The results of modeling have shown that during the LGM, the runoff of the EEP rivers was considerably decreased ( $50 \%)$ and provided strong regression of the Caspian and Black Seas. Comparing our modeling results with geological evidence, we suppose that simulated conditions reflect the so-called Atelskay regression stage of the Caspian Sea and the so-called Postkarangatskay regression stage of the Black Sea (Varushenko et al, 1987; Svitoch, 2003). This

Table 3: Annual volume at $21 \mathrm{ka}$ BP of the EEP river runoff $\left(\mathrm{km}^{3}\right)$ into different ocean basins, simulated by the ensemble and the "successful" PMIP1 models

\begin{tabular}{|c|c|c|c|c|}
\hline \multirow{2}{*}{ basins } & \multicolumn{2}{|c|}{ Black Sea } & \multicolumn{2}{c|}{ Caspian Sea } \\
\cline { 2 - 5 } GCMs & runoff, $\mathrm{km}^{3}$ & deviation & runoff, $\mathrm{km}^{3}$ & deviation \\
\hline ENS & $\mathbf{2 3 2}$ & $\mathbf{- 2 2}$ & $\mathbf{1 1 5}$ & $\mathbf{- 3 9}$ \\
\hline SUCS & $\mathbf{1 7 1}$ & $\mathbf{- 4 5}$ & $\mathbf{8 3}$ & $\mathbf{- 5 6}$ \\
\hline
\end{tabular}

For definitions, see Table 1; 'Relative deviation from today's value (\%)

lends credit to the idea of the connection between Late Quaternary glacial/ cooling/drying planetary events and deep regression states of the Caspian Sea and the Black Sea.

\section{ACKNOWLEDGMENTS}

This research was funded by the Russian Fund for Basic Research. More information about PMIP is available at www-pcmdi.Inl. gov/pmip and www-lsce.cea.fr/pmip2.

\section{REFERENCES}

Joussaume, S. and Taylor, K., 1995: Status of the paleoclimate modeling intercomparison project (PMIP). Proc. First International AMIP Sci. Conf: 425430. WCRP 92, WMO/TD 732, Geneva.

Kislov, A.V., and Surkova, G.V., 1997: Simulation of the Caspian Sea level changes during the last 20000 years. In: Benito G., Beker V.R and Gregory K.J. (editors) - Palaeohydrology and environmental change: 235-244. John Wiley \& Sons, Chichester.

Svitoch, A.A., 2003: Marine Pleistocene of Russian seashore. GEOS, Moscow, 362p. (In Russian).

Varushenko, S.I., Varushenko, A.N., Klige, R.C., 1987: Level changes of the Caspian Sea and closed lakes in the past. Nauka, Moscow, 255p. (In Russian). 